\title{
Lost in Translation: Adaptation of Mating Signals in Changing Environments
}

\author{
Gemma L. Cole
}

Received: 18 March 2013/Revised: 28 May 2013/Accepted: 10 July 2013/Published online: 20 July 2013

(C) Springer International Publishing AG 2013

\begin{abstract}
Competition for mates is often intense and the ability of an individual to attract a mate is highly dependent on the traits that enable an animal to compete and communicate effectively with conspecifics. The animal's sensory system must be tuned to receive and process specific information and such information must be relayed clearly and efficiently. Signalling individuals must also assess their environment in order to produce a suitable signal, and possess the apparatus required to produce this signal. Traits that provide such signalling opportunities do so provided that the signalling behaviour or trait, sensory reception and surrounding environment facilitate both transmission and reception. If the surrounding environment is altered in any way, then this can compromise either signal transmission or reception or both, so communication is likely to break down. It is therefore important, and often essential, that animals have a plastic response to such changes in order to attract mates, avoid predation and find food resource in changing environmental conditions. Three 'critical signalling factors', signal (behaviour/trait), response (signalinduced behavioural response) and sensory systems should co-evolve to ensure reliable communication. This review discusses the interaction of sensory ecology and the environment in shaping signalling and decision-making within mating systems.
\end{abstract}

Keywords Sensory drive · Sensory bias · Behaviour . Evolution $\cdot$ Plasticity $\cdot$ Sexual selection .

Communication

\section{G. L. Cole $(\square)$}

Centre for Integrative Ecology, School of Life and

Environmental Sciences, Deakin University, Geelong, VIC, Australia

e-mail: glcole@deakin.edu.au

\section{Introduction}

Animals communicate for a number of purposes and have developed a vast repertoire of signals in order to achieve this accurately. Because signals that are attractive or conspicuous to intended receivers are also susceptible to detection by predators, parasites and competitors, they frequently represent a trade-off between opposing selective directions. This constraint is apparent in many signalling systems [49, 59, 72, 113, 115, 195] but is further limited by another consideration, environmental stochasticity. The environmental conditions in which a signal is communicated will have consequences for the emission, transmission and reception of the signal which in turn can alter the behavioural responses of the receiver. An environmentally altered signal can therefore have important consequences at both the individual [217] and population [135, 184] levels by altering immediate individual behaviour and/or longterm evolution. It is thus essential that signals are tuned to the environment in which they are used, especially if such signals represent a part of mating behaviour.

In order for a signal to be effective, three 'critical signalling factors', the signal itself, the receiver's sensory system and the receiver's response, must be in tune with the environmental conditions that carry the signal [69]. If, in a changing environment, one or more of these factors is disrupted, the ability of a receiver to interpret the communication may become impaired or lost entirely. For example, if light environment is changed, visually based signals may become altered therefore affecting the reception and interpretation of the receiver, resulting in a changed, or absent, response. The consequences can be problematic if this signal limits or alters detection by potential mates or if the signal is intercepted instead by eavesdroppers such as predators or competitors. In such 
cases it would be expected that selection should act to restore the efficacy of the signal in the new environment, through any of the critical signalling factors. This has indeed been shown in a variety of species [39, 59, 80, 87, $97,135,142,145,177]$. Furthermore, the adaptive nature of each of the three critical signalling factors has been demonstrated individually [74, 88, 93, 94, 134, 185] providing evidence that selection drives evolution via such sensory functions.

\section{Sensory Drive}

The Sensory Drive hypothesis [64], stipulates that the three critical signalling factors, senses, signals and responses, will co-evolve and that signal transmission relies on several co-adapted traits which are influenced by differences in environmental conditions. The model predicts that changes in the signalling environment will influence the evolution of signalling traits, signalling behaviour and behaviour of receivers. This in turn will influence the evolution of habitat choice, the sensory system and brain, leading to multiple cycles of correlated selection on the senses, signals and signal responses. Although sensory drive can apply to any process that affects the outcome of an individual's fitness, predation [59], competition [76] and foraging behaviour $[173,191]$, it is most widely studied in the context of sexual selection. For example, males that create a signal best matched to stimulate a female's senses in a given environment will out-compete those that produce a poorer signal. Within the context of sexual selection, sensory drive has the potential to work via a number of mechanisms: neuronal processes, genetic regulation, behavioural plasticity and sensory systems. The field of sensory ecology teases apart these interactions and studies have demonstrated all parts of the process, although they have yet to demonstrate the process as a whole. Methods to date include phylogenetic analysis of traits and behaviours $[8,9]$, genetic studies on the linkage of preference and trait [88], field experiments [59] and molecular studies [30, 185]. Testable hypotheses include: (i) animals living in similar environments use similar signalling patterns and should evolve in a similar direction, (ii) habitat specificity should bias the direction of selection, (iii) successful communication in a given environment should be derived from the fewest number of evolutionary changes, (iv) animals should lose costly traits that are no longer suited to the signalling environment, and (v) sensory environmental change should lead to predictable gains and losses of signal, signal response and sensory traits.

Sensory drive is thought to occur within many different animal communication systems [72, 80, 87, 135, 142, 177, 198] and provides one explanation for differences in mate choice between [72, 87] and within [135] populations of the same species. For example, guppies use highly developed vision [207] to detect food, mates and predators, and it has been shown that changing signalling environment leads to evolution in signals, mate choice and behaviour [63, 64, 66-68, 94, 129]. A fundamental study demonstrated that populations subject to different light conditions in different locations are subject to different visual environments [63] and exhibit different mating preferences [72, 112] and evolutionary responses to predators [59, 60]. The importance of sensory drive should not be underestimated; it is thought that this process can lead to speciation through sexual selection in some systems [19, 20, 72, 135, 184]. Figure 1 shows a simplified version of the interactions involved.

An intriguing subject, aspects of the sensory drive theory are easily mis-interpreted. One such element is that linkage or pleiotropy must be present between trait and preference for sensory drive to be, or have been, operating. Indeed, such occurrences may take place over time; however, the absence of such factors does not necessarily indicate an absence of sensory drive which only requires a cause-effect relationship between the three critical signalling factors. All that is needed is correlational selection [24, 67]. Another is that sensory drive does not have to be mutually exclusive of other sexual selection processes, in fact it is an integral part of it [64, 70]. Furthermore, when considering the animal sensory system, care must be taken not to anthropomorphise characteristics and carefully consider differences between human and animal senses [12, 62]. For example, when investigating the visual environment, it is necessary to consider the spectral range that animals use, and how they sense it; as this is usually very different from humans. This is especially true of senses that we do not posses and therefore must work harder to understand. The importance of these aspects vary from system to system for example the presence of UV colouration is important in many species $[13,43,100,171]$.

\section{Pre-existing Biases: A Possible Origin of Signals}

The coupling of signals to their environment is futile if the signal is outside the sensory range of the receiver. The accurate detection and interpretation of information delivered by the signal are essential for successful communication. One way in which males can ensure reception of their sexual signals by females is by taking advantage of pre-existing sensory mechanisms within the female's sensory system. The generation of many sexual signals is thought to have originated from initial exploitation of female sensory biases $[8,9,36,70,163,164,175,177$, $210]$. The process of sensory bias posits that mating signals 
Fig. 1 Outline of the sensory drive model adapted from Endler [66]. The model indicates the interactions between the major elements involved in signalling behaviour. The large bubble arrows indicate the interaction between signal, environment and sensory system, the orange dashed bubble arrows indicate the action of sensory exploitation (discussed later in the paper). The black arrows indicate the direct mechanisms of feedback and potential directions of signal evolution (Color figure online)

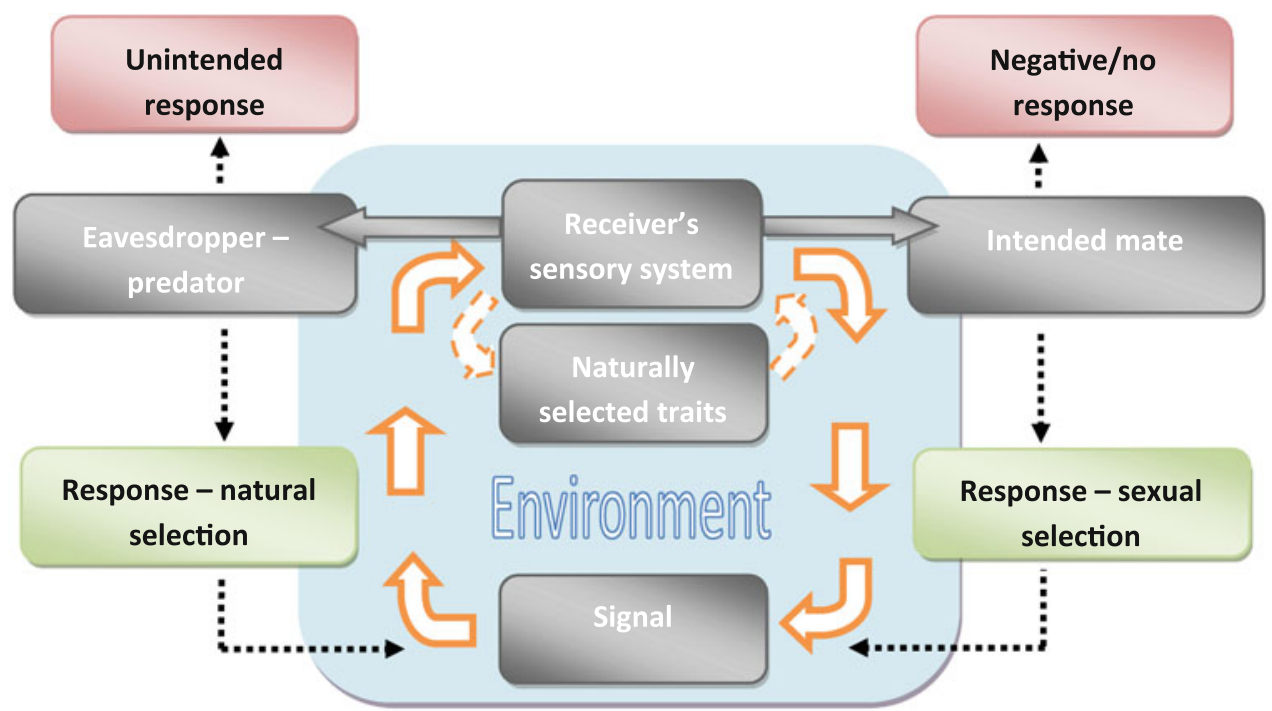

evolve as a by-product of naturally selected communication systems which are already pre-adapted to the environment.

The term 'sensory bias' is often used to cover a number of processes: sensory exploitation, sensory traps and preexisting bias. The differences between these processes are subtle and often hard to determine but the distinction is important. The process of sensory exploitation predicts that sensory system properties affect perception and subsequent behaviour of an individual, sensory traps predict that existing neural processes are co-opted into a new context and pre-existing biases occur where existing properties in the sensory or cognitive pathways bias preferences for certain traits [70].

One of the earliest studies providing evidence for the existence of sensory bias in a behavioural context was Proctor [163, 164], who recorded male water mites mimicking the vibrations that females used to detect prey. Through manipulatory experiments Proctor [163] found that food deprived females would respond more readily to males using this behaviour indicating that the female's first motivation is for prey detection rather than mate detection. Furthermore, a phylogenetic analysis [164] indicated that hunting behaviour preceded the male use of vibratory cues providing further evidence of males exploiting innate female behaviours. Similarly, a female preference for orange food translates into a natural preference for orange mates through a tuned sensory system for this colour in guppies [80, 106, 173]. Colouration in this instance comes from carotenoids which are red and yellow pigments that most animals are unable to synthesise and therefore must get from their environment $[59,101]$. It has been suggested that this is a sign of genetic quality $[59,128]$. Interestingly, zebrafish show a similar bias towards red colouration despite no use of this colour in mate detection or assessment [193] suggesting that a pre-existing preference for red may play a part in their evolutionary history, possibly resulting from detection of food. Other examples of sensory bias include the swordtail characin, Corynopoma riise $i$ where males develop an opercular flag, which varies within populations with the abundance of prey, in order to mimic prey and act as a lure to females [5], a female preference for 'hooded' burrows for escaping predators, which is exploited by male fiddler crabs [37, 38] and complex calls in the Tungara frog, Physalaemus pustulosus, which have evolved over simple calls due to the nature of female's auditory senses [176].

Demonstrations that female preference pre-dates male sexual traits have been conducted using phylogenetic analysis, providing further evidence that sensory bias can indeed be looked upon as an origin of female preference for male signals in some species $[8,177]$. Although no link has been reported between mate preference and food colour in some species such as killifish [88] and bowerbirds [17] there is some strong evidence to support this theory and these studies may require larger sample sizes and more extensive phylogenetic coverage to uncover such links. A thorough knowledge of a species' evolutionary ecology is also required as biases may originate from factors that are present in native habitats and not in more recent range expansions, or that are now absent from native habitats. This may be true of the latter example where satin bowerbirds feed on the blue fruit of the blue quondong tree whilst using blue as a preferred colour in mate choice.

\section{The Decision to Produce a Signal}

The first stage in the emission of a signal is the decision of how, when, and where to produce a signal that ensures the 
best chance of detection by intended receivers. Sexual signals have generally evolved to be conspicuous to potential mates at given times, locations and positions; the horn of the beetle Coprophanaeus lancifer, is coloured to contrast with ambient forest light in order to maximise female perception at signalling times [198] and the signalling apparatus of the wolf spider, Schizocosa ocreata, contrasts sharply with background when viewed from the perspective of the female whilst remaining inconspicuous to predators [39]. It is important that signals are accurate to avoid unbalancing costs and benefits where inefficient signalling would increase potential predator/competition costs with lower mating benefit. Although signals are generally well adapted to specific environments animals must overcome environmental stochasticity in the short term in order to produce effective communication to ensure reproductive fitness, this is particularly true of those living in highly changeable environments $[25,153]$.

The decision to produce a signal at a particular time and place should be influenced by factors that potentially interfere with the signal such as habitat type, background interference, location, timing, type of signal and probability of detection by intended receivers and eavesdroppers. This initial decision requires the signaller to be aware of its environment and to be able to detect and react to changes that will potentially alter detectability by intended receivers, forming a complex problem for many species. For example, more dense habitats will produce different signal interference to open habitats [151, 212], signals emitted at height will disperse more and further than those on the ground [22] and certain visual signals will be more effective against different backgrounds. Additionally, chemical signals not only travel faster in higher temperatures but also fade faster $[18,167]$. Adding to the complexity of this initial decision is the approximate position of the intended receiver [126], and similarly, any competition, predators or parasites. Furthermore, combinations of these factors are likely to change over minutes, hours, days and seasons. A decision process to ensure the most effective signal is produced given the environmental conditions would give an animal the best possible change of overcoming these issues.

The examples above represent just a few factors that animals should consider when producing a signal. How the initial decision is made however, is not well understood. Behaviour that suggests this decision process does exist has been reported in a wide range of animal taxa. For example, males of both Lawes' bird of paradise and bowerbirds leave their display courts on the ground to travel to the forest canopy where they use acoustic calls to attract females from further afield [86, 165], animals have been shown to alter the position of their courtship displays to ensure optimal lighting and visibility to potential mates
[73, 198] and detection of temporal gaps in the wind is used to improve reception of vibratory signals [145]. Further examples follow below.

The extraordinary ability of animals to solve novel problems is becoming well-known, and the ability to solve problems is part of daily life for most animals. There are some very effective ways of mitigating the effects of environmental change although both the long- and shortterm mechanisms that facilitate such processes are poorly understood. For example, it has yet to be asked what are the mechanisms for detecting a change in environment and what is the decision process for enabling this change? Are these behaviours innate, are they learnt and do individuals carry out such decisions on a case by case basis? Are these traits a result of direct sensory reception of the environmental conditions, experience, or a lack of a detected response from the receiver? Experimental studies may be useful in detecting cues that initiate signalling decisions and monitoring environmental threshold values that trigger a simple signal adaptation such as increasing the rate of emission or amplitude of the signal. Although such studies may be viable in the lab, recreating these in nature will pose more of a problem. Suggestions have been made into the role of receiver responses as cues for altering signalling behaviour [107] although more work will provide clearer answers.

\section{Signal Emission and Tuning to the Environment}

After the initial decision to produce a signal has been made, an animal must have the energy and apparatus to emit a signal that is tuned to the environment. Signals can be generated via a number of pathways and each signal will be limited in the type and amount of information it can carry as well as the distance that it can travel. The diverse array of signals all serve the purpose of transmitting information, environmental conditions, the type of recipient, the information transmitted, distance to receiver and energetic cost all have important implications in signal emission.

The energetic and physiological requirements to produce a signal vary. The amount of energy required to produce different signals will be influenced by the amount of energy available to the animal. Habitat not only has direct effects on the effectiveness of a signal, but may also limit the type of signals that are physically possible for an animal to produce through indirect factors such as food availability or composition. For example, animals with low energy diets may be unable to produce signals requiring high energetic outputs [14, 137, 156]. Similarly, animals in challenging environmental conditions or high predation areas may be limited in the amount of energy and time 
available for signal production and emission [156]. Furthermore, environmental variation may be directly correlated with the intensity of sexual selection and it is this that affects sexual signals. For example, birds breeding at higher elevations are subject to colder climates and shorter breeding seasons resulting in higher energetic costs linked to foraging and brood care in both parents [7]. This difference in life histories has created more intense sexual selection at lower elevations which in turn produces divergence in sexual signals across elevational gradients [192]. Other indirect effects include the need to remain inconspicuous; the whistle communication in killer whales is less complex in mammal eating species than in fish eating animals [172] possibly to avoid detection by mammalian prey.

The amount of energy required to emit a given signal and the amount of information a signal can carry are important considerations. For example, chemical signalling is one of the most primitive signals and requires less energy than producing either acoustic calls or behavioural courtships [22] but may be restricted in the amount of information it can carry. The importance of this however, varies between species; the amount of information required for a signal to be effective depends on the minimum value to elicit a response in the receiver which may only be a cue to determine the presence of a potential mate. A signal containing a low amount of information does not therefore have to be poor if the information is of high value; the quality rather than the amount of information emitted should minimise the occurrence of mistakes, increasing the chance that the receiver interprets the signal correctly. Selection should thus favour signallers that produce more efficient signals of high value, rather than high information. The evolution of more efficient signals relies on the balance of cost and benefit; a signal can only evolve under conditions where the benefits outweigh the costs (for both the emitter and intended receiver) and this is more likely if the energy requirement is decreased (potentially by decreasing information amount and increasing value).

In order to emit the required information, animals must have the correct apparatus given the environment and this apparatus must function efficiently in order to minimise the amount of energy required to emit a signal. Physiological structures that enable an animal to emit a signal are varied and are adapted to the type of substrate through which the signal must travel. For example, acoustic communication is produced through vibrating structures and must overcome environmental factors such as acoustic impedance boundaries, attenuation and background noise. This requires the use of specialised structures which amplify signals and closely couple them to the environment in order to propel them through the medium. Although the structures used to produce sounds use the same principles, they often differ in structure. Both mammals and anurans use larynx to create sounds, however anurans (and some mammals such as gibbons) have developed a vocal sac in order to amplify their call (compensating for size) which is more effective than the larynx alone. Air in these vocal sacs has been found to closely match the acoustic impedance of the surrounding air allowing the sound to travel further [141]. Even with these adaptations only a small amount of energy produced by the frog is used to create the sound signal [174]. Additionally, the swim bladder has been co-opted to produce acoustic communication in some fish [170]. Different types of syrinx exist within birds to create acoustic signals and these are specialised to allow the production of different types of calls, such as the rapid song of some songbirds [99]. More adaptations can be seen in other animals; high intensity sounds are required to travel large distances and as such insects transmitting signals over distances have developed ways of creating signals using external structures such as foliage or modifications of the exoskeleton $[54,83]$. Hairs and bristles assist emission of chemical signals in vertebrates $[136,152]$ and visual signals optimise the light wavelengths available to them $[55,65,100]$.

The energy required to use and maintain such apparatus can be high and physiological trade-offs have been reported which compensate for this. For example, energy expenditure increases with light intensity in fly vision [157], animals that live in dark environments, have a reduced visual thalamocortical system (an area in the brain responding to visual stimulus) and an increased somatosensory system responding to stimuli in the skin such as touch [31]. Furthermore, developmental plasticity in the cortex of mammals [121] may enable them to adapt more readily to novel environments.

The environment can have very strong effects on the energetic and physiological requirements for signal emission. Not only can the environment dictate the energy required to produce a signal but can also limit the amount of energy available to an animal through diet and other challenges such as the energetic requirements of thermoregulation etc. A trade-off also exists in the amount of information and the quality of that information. A signal of low quality, high information will not be as efficient as that of high quality, low information. This balance is likely to be dictated by the information required by the receiver, the probability of interception by eavesdroppers, the energy required and the apparatus available.

\section{Transmission and Environmental Effects}

The effect of the environment on animal communication has been documented in many species $[4,11,26,27,57$, 146, 154, 178, 180]. Signalling environments can have 
many different effects on the transmission of a signal and signals in both the terrestrial and aquatic environments are subject to limitations and as fluids are essentially governed by the same physical laws [50]. Environmental conditions can alter the structure and content of a signal having both direct (direct effects alter the chemical, physical or biological composition through interaction with the signal itself) and indirect impacts on the accuracy of communication through a number of factors such as background noise, habitat structure, lighting and climate; indirect effects alter signal generation, transmission and reception through factors, such as pollutants $[6,56]$ and diet $[105$, 106].

Animal signals are susceptible to distortion by environmental factors which will limit the type and efficacy of certain signals in a given location. Examples of this include the masking of acoustic communication in noisy environments [11, 85, 216], limitation of chemical detection in nutrient rich [201, 217] and chemically complex environments [148] and alteration of the light spectrum by the environment in visual communication [65, 73, 217]. In addition, the physical properties of a habitat (e.g. structure) can also hinder communication through various forces such as attenuation, reverberation and turbulence. Climate and location have many effects which include, within the terrestrial environment, wind [1, 46, 58, 145, 212], elevation [119], reverberation [190, 212], noise [11, 26, 108, 154, 180, 188], background movement [82, 161], light [51] and temperature $[54,206,212]$ in the terrestrial and turbulence [131, 148], velocity [208], viscosity [131] and $\mathrm{pH}$ [111] in the aquatic.

The effect of these processes on animal signalling has been demonstrated in a variety of taxa. For example, temperature is known to affect chemical emission rates in insects [143], background interference affects weakly electric fish (that communicate using electrostatic pulses called electric organ discharges and are known to function in mate choice in some species) [44, 187] and echolocation in bats $[4,57]$. The transmission properties of a signal are, however, often coupled to habitat type and there are some intriguing results in this field, best demonstrated by work on acoustic communication (for a review see [77]). Acoustic communication is found to be compromised by environmental factors in frogs $[11,196]$, primates $[27,78]$ and fish [204], although studies on avian communication most clearly indicate the relationship between habitat type and signal. A study by Wiley [211] investigated the relationship between habitat and call characteristics in 120 species of bird in the group and reported a correlation between habitat type (six habitats corresponding to forest and open habitat) and certain call structures, providing evidence that habitat structure can predict vocal communication in the group Oscine. Tobias et al. [200] studied song divergence between closely related 'bamboo-specialist' bird species in two types of Amazonian forest and found that divergence was more strongly correlated with the transmission properties of the habitats than any other factor. These results have also been reported in white-crowned sparrows [52], greybreasted wood-wren [53] and forest warblers [119]. In addition, Gish and Morton [97] investigated the characteristics of bird songs in native and non-native habitat; Carolina wren songs were played in two different habitats in order to determine the suitability of the song to their native habitats. Results showed that songs retained more of their original characteristics in native habitat. This highlights not only the difference in sound transmission between habitats but also song adaptation to a specific habitat and the potential for breakdown of the signal in mal-adapted environments. Morton [151] compared the sound propagation properties of three habitat types and discovered that they indeed differed, influencing the type of signals suitable for each habitat. Similar results were also found by Daniel and Blumstein [45]. Such differences in transmission qualities can impose divergent selection on signals between similar habitats (forests [200, 212] as well as 'opposite' habitat types (open vs. closed habitats [178]), mixing of signals is faster in open habitat than in forests [58], illustrating the importance that the transmission properties of a habitat have in shaping signalling behaviour.

The location within a habitat can also influence signal transmission for example in the aquatic environment, the type of sediment moderates turbulence and velocity [215] and sediment particle size has an effect on signal transmission with finer sediments facilitating signals over longer distances [149]. Signal generation can be further complicated by the environment affecting different parts of a signal differentially [48]. Signals that therefore require specific ecological conditions or specific microhabitats to transmit will be limited to use in either a specific microhabitat, position within the microhabitat or time of day. That animals do alter such aspects of signalling behaviour to overcome environmental constraints, has been shown.

\section{Location}

Location alone can mitigate many environmental factors if chosen carefully. For example, hyenas adapt scent marks depending on habitat to maximise detection by conspecifics [136] and male Bactrian camels use their humps to apply scent markings, increasing their signal range using the highest part of their body [209]. Animals using visually based signals are prone to interference from objects in the line of view and can only reflect the wavelengths that are available in a given place and time; therefore, location is particularly important in ensuring detection. Animals have been shown to alter the position of their courtship displays 
to ensure optimal lighting and visibility to potential mates [73, 198]. A study by Nemeth et al. [155] investigated song-post height in antbirds, reporting that species were able to optimise the transmission of their song by choosing specific heights from which to sing.

\section{Signal Timing}

Call timing can be an adaptive response to environmental noise. Fuller et al. [92] found robins inhabiting urban areas would restrict their singing to periods of low anthropogenic noise in order to increase the transmission and accurate reception of their communication. Zelick and Narins [220] demonstrated that males of two neotropical treefrogs suppressed calls in response to bursts of noise which encompass the principal frequency components present in their vocalizations. Wind-speed and turbulence tend to be highly variable and animals signalling in such areas must be able to change behaviours in a short period of time. Treehoppers communicate using plant-borne vibrations which have the potential to be disrupted by external vibrations induced by the environment; McNett et al. [145] discovered that males use gap detection to time their signals to periods of low wind, limiting interference by high wind and enhancing reception by females. Incidentally, wind speed also affects the mate searching ability of the aphid parasitoid, Aphidius nigripes, where wind speed represents a trade off between the dispersion of chemical cues and male flying ability [138]. Thomas et al. [199] investigated signalling plasticity in the Australian field cricket, Teleogryllus oceanicus to discover that males increased their use of chemical cues during times of low group courtship song, a possible adaptation to compensate for the lack of amplitude from a group chorus, and Endler and Théry [73] investigated the courtship behaviours of three forest-dwelling birds showing that each species would alter its behaviour to coincide with optimal ambient light conditions that best show off their colouration. Timing of calls is very important in not only ensuring receiver response, but also in increasing conspicuousness of the signal to detection by predators. In some cases careful timing can maximise visibility to mates whilst minimising visibility to potential predators $[61,63,73]$. Time detection is a clever way of mitigating environmental effects but is not well understood.

\section{Mode Switching and Multimodality}

Multimodality is defined here as the use of a number of signal types (received via different sensory systems), either individually or simultaneously, within a single signalling event. Multimodality is known to be an important aspect in animal communication, that can either enhance reception of a signal when a number of signal types are used together
[122, 202], increase the amount/type of information transmitted [158] or offer an alternative channel when one channel becomes ineffective [116]. The use of more than one type of signal, either singularly or simultaneously, is an effective way of avoiding environmental interference and coping with stochasticity to ensure accurate reception by intended receivers. This is not to suggest that one type of signal is necessarily used instead of others within a given individual, but refers to the principal sense used in a given situation. Mode-switching behaviours include changing between visual and olfactory senses [51], visual and seismic [213], acoustic and olfactory [199] and echolocation to visual [57]. For example, animals that must display in both the light and dark will frequently encounter conditions where some signals are no longer the most efficient form of communication. In order to cope with this many species will switch from visual to olfactory cues as in alpine newts [40, 51] and guppies [33]. Additionally, male sticklebacks substitute visual for chemical cues for long distance attraction of females [144] and males of the wolf spider (S. ocreata) switch between two types of signal, seismic and visual, depending on the substrate on which he is courting [102]; a behavioural response to environmental change whilst remaining inconspicuous to predators.

The use of different signalling channels simultaneously can be used to enhance signals or to increase the amount of information within a single event. The use of multiple signals has been seen to increase pollination attempts [122] and mitigate environmental stochasticity [117] in flowers, provide context specific signals in cowbirds [158] and increase female approach rate to male fire-belled toads [221]. Multimodality is undoubtedly an effective way of coping with environmental variation or change but this option is generally limited to those with very local small scale or clumped distributions; those species with larger territories are limited by the number of reliable signal types effective over larger ranges and more microhabitats. Limitations are also likely to occur due to energetic trade-offs in the apparatus required to emit more than one type of signal.

\section{Bandwidth Selectivity}

The masking of signals by background noise can pose a problem to many species. This masking can come from a number of sources including anthropogenic [26, 85, 189], conspecific [96, 197], heterospecific [23, 95, 132] and natural $[16,103]$. Bandwidth selectivity, the use of signal components that are selected specifically to mitigate background noise, can play an important part in shaping animal communication. For example, frogs have avoided acoustic masking from low frequency abiotic noise with the use of high frequency vocalisations $[16,103]$, with similar results 
recorded in birds [189]. In contrast primates have been shown to select low frequency calls for long distance propagation [147].

Visual signals have been shown to use components that contrast specifically with environmental noise. For example, behavioural displays in reptiles use movement components that differ from background vegetation movements [160-162]. The bright plumage of female eclectus parrots reflects wavelengths that contrast with those reflected by the background [110], this has also been reported in reef fish colouration [140], lizards [124] and bowerbird decoration use [71]. Electrically communicating fish have been shown to modulate the frequencies of their signal in times of interference [28]. Borean tree-hole frogs use water-filled tree holes to amplify their calls by tuning their vocalizations to the resonant frequency of the hole thereby increasing their chances of being heard by females. What's more the frogs are able to assess the holes according to how much water they contain and adjust their calls accordingly [123]. Other mechanisms for overcoming background noise include partitioning signal components in species that share the same spatial and temporal signalling space [132] and receiver sensory systems which are finely tuned to receive conspecific signals [181, 214].

\section{Adaptation of Courtship Behaviour}

Visually based behavioural signals are well researched and many effects of the environment including lighting, vegetation movement and background contrast have been studied. One such example is that of the head bobbing display of anoline lizards which is designed to attract females and serve in male competition. This display is often performed in areas of wind-blown vegetation which has the potential to disrupt the successful communication of the signal. Fleishman [82] investigated the mechanics of head bobbing and discovered that in order to be effective the display had to be conspicuous against the background and did so in several ways; the display was carried out with high velocity, high acceleration and high amplitude, all characteristics that differed to the background movement of vegetation. Additionally, the amplitude of this display is thought to maximally stimulate females' visual system from within the territory of the male and the speed of the movement is adjusted according to environment [160]. Similar results are found in the push-up and tail flicking displays of the Jacky dragon [161, 162]. Other examples of males adapting courtship displays to compensate for varying light conditions include male guppies. Male guppies have two distinct mating behaviours, sigmoid courtship display and sneaky (non-consensual) [98]. Chapman et al. [32] studied the relative frequency of these behaviours under varying lighting conditions and found that under good visual conditions males carried out sigmoidal displays at a higher frequency than sneaky copulations and vice versa in poor visual conditions, indicating that males adapt aspects of their mating behaviour to compensate for the visual senses of the female in varying environments. This behaviour is also a way of reducing predation when predation pressure is correlated to ambient lighting intensity [61]. Males have also been shown to adapt mating distance from females in different light intensities to optimise signals to females [130]. Behavioural modification of structures or courts built has also been exhibited by some species in order to enhance visual contrast to increase conspicuousness to females, such as in the case of the bowerbirds [75] and golden-collared manakins [203]. This result demonstrates the importance of plasticity in signalling behaviour and ability of an animal to detect the environment and adapt accordingly.

The transmission properties of the aquatic environment also affect behaviourally based signal transmission. The transmission of light through water is dependent on a number of factors including depth, turbidity, mineral composition and submerged matter [127] which can in turn alter the perception of visual signals. Turbidity is one such factor that has been found to distort visual mating systems [217] and this has been found to break down systems to the extent that different colour signals are no longer distinguishable to receivers, causing hybridisation and limiting the promotion of diversity in some fish species [183]. Depth is another factor that has been found to affect signalling in the aquatic environment, particularly visual cues. As light travels deeper, the physical properties of the water change and different wavelengths are absorbed with increasing depth and water type [127]. For example, as water in clear lakes gets deeper it absorbs longer wavelengths in the red/orange spectrum and the prevailing light colours will be the shorter wavelengths, UV and blue. This, therefore, affects perception of colour in different depths, where the most conspicuous will be the opposite to those absorbed. It has been found that this absorption of wavelength can predict the colour of sexual signals in some fish species, most notably the cichlid which is thought to have speciated due to the partitioning of light in this way [135, 183].

Plasticity within sexual signalling is vital for many species; however there are some that lack this ability. The stability of a habitat may influence whether an animal is able to adapt uniform signalling behaviour; species that live in more stable habitats may not have evolved this flexibility and local environments may change in a novel way that exceeds the capacity for the animal to cope. For example, if an animal is required to make a decision on unfamiliar factors or if animals are physically unable to carry out the required behaviour it may be difficult for an animal to persist in an area. An example of the latter may be seen in 
birds using acoustic signalling. Francis et al. [85] undertook a study of the effects of anthropogenic noise on communication in two subfamilies of flycatcher, the grey and ashthroated. With increased background noise grey flycatcher abundance declined whilst ash-throated flycatcher persisted but with an increase in call frequency to compensate. This adaptive response was not recorded in the grey flycatcher. Whether this response is an adaptation to environmental noise has been questioned however as an increase in frequency is not as effective at mitigating background noise as an increase in amplitude [11, 27, 154]. Additionally, many confounding variables in such studies render it difficult to determine the sole cause of changes in behaviour and why some species are able to adapt, whilst others are not.

The signal transmission properties of an environment can include both the physical composition of the transmission substrate or the physical properties of the surrounding habitat and both play an important part in determining the signalling pathway for many animals, especially those that must transmit a signal over large distances. Many animals cope with this well. However, it is less clear to what extent animals are able to change signal composition in order to overcome environmental effects. Some signal types that are immediately plastic, such as call amplitude, enable an individual to overcome immediate effects of transmission environment without altering the detection by, or response of, the receiver. Those species with more fixed signal types however, such as colour visual cues, are often unable to change the nature of their signal. This will promote evolution through the most evolutionary responsive factor which may be the sensory systems, or response of, the receiver.

\section{Sensory Systems and Reception}

Sensory systems match the profile of that which they are detecting (after the signal moves through the environment) [3, 114, 133, 169, 214]. The adaptation of senses to changing environments has been demonstrated in many species [74, 88, 93, 94, 134, 185]. Adaptation can include plasticity within the sensory system (a change within the physiology of a particular sense) or between sensory systems (switching from one sense to another) and can be dictated by genes, internal processes pathways, developmental strategy and environment. Furthermore responses can be indirect effects through hormonal or dietary effects $[6,105,106]$. An example is the effect of chemical pollutants on the olfactory ability of fish [15, 125] which can be due to the detection of chemical thresholds in noisy chemical environments [223] and/or physiological disruption of sensory systems [84].

Despite chemical signalling being one of the most common forms of communication in the animal kingdom, few studies have looked at the plasticity of this system. It is known that the detection of chemical signals is susceptible to interference through a number of factors such as masking by other chemicals [81, 205], disruption of the internal (biological) signalling pathway [47] or interference with the sensor itself [159]. However, whether these systems are plastic has yet to be thoroughly investigated and studies generally focus on the behavioural consequences, rather than physiological mechanisms. Plasticity of chemoreceptors in Drosophila melanogaster has been demonstrated in relation to social environment [222] but whether this is also true of habitat is unknown.

A comprehensive example of sensory adaptation can be found in the visual system. The environment can influence visual systems in several ways such as perception, changes during development and genetic changes. Studies of plasticity within the visual sensory system have discovered several aspects of vision which alter in animals raised under different light conditions such as oil droplets [109], retinal filters [34, 35, 41, 42], lenses [120, 179], cone cells [186] and opsin expression [91] which may translate into changes in the perceived colour of mates. Tuning of the visual system can be achieved by several mechanisms including turning opsin genes off or on [21], shifting the wavelength absorption of a chromophore (by shifting between porphyropsins and rhodopsin types) and changing the amino acid complex of an opsin [21, 218, 219]. Furthermore, vision has been shown to change during development in many animals [10, 185] and be further tuned in adults [2] which may be implicated in the detection and assessment of mates [134].

\section{Decision-Making and Responses}

Decisions based on cues will certainly influence the direction of evolution. The outcomes of such decisions can be minimal on the individual level but could lead to divergence, hybridization [81] and even speciation [135, 184]. The driving factor of these processes is the altered perception of mates and/or interpretation of mating of signals that force selection in different directions. The absence of long-term, evolutionary, adaptation or shortterm plasticity will inevitably lead to exclusion of the species from certain locations [85].

The behavioural responses of the receiver complete the signalling process and is a critical step in driving diversification through sensory drive. This is the point at which the signal emitter discovers whether the signal has been successful in obtaining a mating. There are three main responses that can occur from a sexual signal, assuming there is a potential mate present: an appropriate response, indicating that the signal has been received and understood, no response, 
which may indicate that the signal has not been received or is irrelevant to the receiver, or an inappropriate response, which indicates that the signal has been mis-interpreted. These responses will all have consequences for the direction of evolution. For example, no response may mean complete breakdown of the mating system and possible exclusion of the species, a mis-interpreted response may result in hybridisation or poor quality mates, and the appropriate response can result in diversification and speciation.

For the most part, researchers have concentrated on female preference as the source of the behavioural response. A thorough example comes from Killifish in which females exhibit a preference for certain male morphs. The effects of a change in lighting environment on mate preference have been investigated by Fuller [87, 88, 93]. Fuller [87] showed the effects of light on female preference of male killifish colour morphs through the conspicuousness of the male trait in a given light environment [87]. Further investigation revealed that this response, both genetic and heritable [89], is key to explaining the relative abundance of colour morphs in habitats with certain water properties. Males also had higher levels of plasticity for these colour morphs (blue males in tea-stained water and red in clear water) respectively in line with predictions that males contrasting to background have higher reproductive success [87, 89]. Furthermore, visual sensitivity to UV and blue light varies amongst populations [90] indicating intraspecific plasticity of the visual senses which may be driving the female decision-making process. This process is also known to drive speciation in cichlids, where environmental conditions alter abundance of male nuptial colouration through increased female sensitivities to red and blue light dependent on photic environment which in turn influences mate choice responses [94, 129, 135, 184].

Differences caused by habitat have also promoted divergence in the calls of two subspecies of cricket frog which may prove a crucial component in the progression of speciation, especially considering the reliance of anurans on vocal communication in mate recognition [95]. Further examples include male warblers in India which maintain conspicuous colouration with respect to background reflectance in order to gain the best territories and influence female responses which are also thought to have played a role in species divergence in this group [139]. Female stickleback [19, 168, 182], guppies [60, 72], Telmatherina sarasinorum [104], southern pygmy perch [150] and cichlids [135, 184] have also been shown to exhibit preference in accordance with background contrast.

The above examples demonstrate altered but still appropriate responses to changed environment. Behavioural responses, however, can also include inappropriate responses and poor decisions, as well as badly timed or delayed responses. Delayed responses to odours have been reported in hermit crabs, where altered $\mathrm{pH}$ disrupts chemoreception [47], limited detection of sex-specific pheromones has been reported of snails in polluted water [194] and a copepod's chemical perception is disrupted in turbulence potentially inhibiting its ability to detect mating signals [131]. Inappropriate responses are at risk of being overlooked and can have extreme consequences as has been seen in species of zebrafish [79] and swordtail (Xiphophorus birchmanni and Xiphophorus malinche) [81]. Fisher et al. [81] investigated the effects of chemically disrupted habitats on the mate preferences of females and discovered that females are unable to determine con- from heterospecifics in such environments which has lead to a possible hybridization event.

Furthermore, the disturbance of the visual habitat has been reported to threaten the diversity of cichlids [183] reversing the diversification that sensory drive promoted through speciation in the first instance. This last example demonstrates the potential strength of the sensory drive process and highlights the importance of fully understanding the mechanisms behind it. In cases where animals are unable to identify conspecifics [81] or where environmental deterioration promotes dishonest [217] or altered [56] signalling the integrity of the mating system can be compromised. Eeva et al. [56] reported that environmental pollution may dull plumage colouration in the great tit having possible effects on mate choice decisions made by females. Wong et al. [217] discuss the opportunity for cheating amongst poor quality males in stickleback where honest signalling in three-spined sticklebacks is compromised by algal turbidity affecting visual conditions in the Baltic Sea. Under turbid conditions poor quality males are able to signal more frequently, something which would prove risky in clear water where they attract competition and aggression from honest, higher quality conspecifics. This interesting result has obvious impacts on the stability of such systems and repercussions for females that choose poor quality males which are more likely to cannibalise her young [29]. Additionally, the effects of altered light environment has been shown to alter the mating decisions in female $P$. pustulosus frogs, when light levels are increased females are less selective, a possible behavioural response to increased predation risk [166].

\section{Conclusions}

The link between signalling environment and signal efficacy has been shown in many species and the effects on mate choice are demonstrated. Pre-existing biases have been shown to form an important aspect of female choice models and can explain the origin of such preferences in some species demonstrating the importance of sensory 
systems in shaping mating signals. The environment plays an important part in shaping the evolution of many mating signals and mating signal evolution is reliant on the coupling of sensory systems to their environment. Further considerations involving the receiver must also be taken into account: a signal must be timed to coincide with receiver presence, it must be received and interpreted accurately by the receiver, the signal must not be easily intercepted by 'eavesdroppers', the signal should be plastic in order to cope with changing environments, and signal generation should not be too costly relative to its benefits to the sender. Males have been shown to adapt all aspects of sexual signalling from courtship behaviour $[32,73,98$, 130] to colouration [87, 93] and even morphology [5] in order to gain female attention in changing environments and these are often within the constraints of predation pressure and mate competition [59]. Used in combination the structural properties of a habitat, climate and disturbance can be used to predict not only the optimal method of communication but also the potential selective pressures acting on communication and mating strategies. These predictions may be important in understanding the longterm effects of changing environments on the persistence of a species in a habitat and impacts on mate detection and choice.

Animals can adapt to environmental change in several ways, but the three critical signalling factors, the signal itself, the sensory system and the receiver response, must co-evolve in order to maintain the accuracy of the signal. Alteration of signal efficacy by the environment has been shown to have a range of effects on animal mating systems. A shift in light environment influences male colour pattern and the relative abundance of morphs [87], algal turbulence has been shown to alter behavioural mating strategies [217], sensory drive has been shown to lead to speciation [135] and background noise can limit the persistence of a species in a given habitat $[85,118]$. Although many species have shown changes in response to variable environments in the long-term, rapidly changing environments may pose a threat to animals unable to adapt or evolve quickly enough to catch up. It is therefore important to understand not only the effects of environment but also the mechanisms by which species are able to cope with such stressors and potential effects on the direction of selection. In order to do this each step in the signalling process must be identified and investigated separately, starting with the initial decision to emit a signal.

The initial stage in the signalling process is the decision to create a signal and, as important as it is, it seems that this initial decision and the mechanisms behind it have been somewhat neglected in literature and need to be addressed. How the emitter interprets the surrounding environment has been shown to influence signalling behaviour, however the cues that initiate this process are largely unknown. Do sensory systems detect this change and if so is this through comparative processes, direct detection, thresholds, experience and learning, or do they use the response of the receiver to adjust their own behaviour? Such answers are important in helping us determine the likely impacts of environmental change on different species. A good starting point is the investigation into how the signal emitter interprets their environment rather than how the receivers sensory system interprets the signal.

Other areas that are in need of attention include the timeframes required for plasticity to restore signal efficacy in times of environmental change and the importance of learning in such processes. A related unknown is how rapidly populations can evolve to match new and changing environments. Phenotypic and evolutionary plasticity are particularly important given present times of rapid change, be it habitat destruction, climate change or pollution. Although physiology and/or evolutionary plasticity may allow adaptation in the longer term, learning (including experience, copying and imprinting) may bridge the gap between the initiation and completion of such changes depending on timeframes. And although sensory bias has been shown in a number of taxa, learning has yet to be ruled out as a driver.

Many aspects of sensory drive have been reported in different species and we have evidence suggesting that sensory functions do indeed play a crucial part in directing selection of signals. The evolutionary and phenotypic plasticity of male trait, female preference, and sensory systems have been shown independently and their link to environmental conditions proven. In order to take research one step forward the full process of sensory drive must be demonstrated and the co-evolution of the three critical signalling factors studied together. Although a daunting task, long-term artificial selection studies will be an effective way of demonstrating the process, piecing together the mechanics of sensory drive as a whole.

Acknowledgments I would like to thank John Endler and two anonymous reviewers for their valuable comments on this manuscript.

\section{References}

1. Alberts AC (1992) Constraints on the design of chemical communication systems in terrestrial vertebrates. Am Nat 139:S62S89

2. Allison WT, Haimberger TJ, Hawryshyn CW, Temple SE (2004) Visual pigment composition in zebrafish: evidence for a rhodopsin-porphyropsin interchange system. Vis Neurosci 21:945-952 
3. Archer SN, Endler JA, Lythgoe JN, Partridge JC (1987) Visual pigment polymorphism in the guppy Poecilia-reticulata. Vision Res 27:1243-1252

4. Arlettaz R, Jones G, Racey PA (2001) Effects of acoustic clutter on prey detection in bats. Nature 414:742-745

5. Arnqvist G, Kolm N (2010) Population differentiation in the swordtail characin (Corynopoma riisei): a role for sensory drive? J Evol Biol 23:1907-1918

6. Baatrup E, Junge M (2001) Antiandrogenic pesticides disrupt sexual characteristics in the adult male guppy (Poecilia reticulata). Environ Health Perspect 109:1063-1070

7. Badyaev AV, Ghalambor CK (2001) Evolution of life histories along elevational gradients: trade-off between parental care and fecundity in birds. Ecology 82:2948-2960

8. Basolo AL (1990) Female preference predates the evolution of the sword in swordtail fish. Science 250:808-810

9. Basolo AL (1995) Phylogenetic evidence for the role of a preexisting bias in sexual selection. Proc R Soc B 259:307-311

10. Beatty DD (1984) Visual pigments and the labile scotopic visual system of fish. Vision Res 24:1563-1573

11. Bee MA, Swanson EM (2007) Auditory masking of anuran advertisement calls by road traffic noise. Anim Behav 74:1765-1776

12. Bennet ATD, Cuthill IC, Norris KJ (1994) Sexual selection and the mismeasure of color. Am Nat 144:848-860

13. Bennett ATD, Cuthill IC, Partridge JC, Maier E (1996) Ultraviolet vision and mate choice in zebra finches. Nature 380:433-435

14. Bertram SM, Thompson IR, Auguste B, Dawson JW, Darveau C-A (2011) Variation in cricket acoustic mate attraction signalling explained by body morphology and metabolic differences. Anim Behav 82:1255-1261

15. Beyers DW, Farmer MS (2001) Effects of copper on olfaction of Colorado pikeminnow. Environ Toxicol Chem 20:907-912

16. Boeckle M, Preininger D, Hödl W (2009) Communication in noisy environments: acoustic signals of Staurois latopalmatus Boulenger 1887. Herpetologica 65:154-165

17. Borgia G, Keagy J (2006) An inverse relationship between decoration and food colour preferences in satin bowerbirds does not support the sensory drive hypothesis. Anim Behav 72:1125-1133

18. Bossert WH, Wilson EO (1963) The analysis of olfactory communication among animals. J Theor Biol 5:433-469

19. Boughman JW (2001) Divergent sexual selection enhances reproductive isolation in sticklebacks. Nature 411:944-948

20. Boughman JW (2002) How sensory drive can promote speciation. Trends Ecol Evol 17:571-577

21. Bowmaker JK (1995) The visual pigments of fish. Prog Retin Eye Res 15:225-240

22. Bradbury JW, Vehrenkamp SL (2011) Principles of animal communication, 2nd edn. Sunderland, Sinauer

23. Bremond J-C (1978) Acoustic competition between the song of the wren (Troglodytes troglodytes) and the songs of other species. Behaviour 65:89-97

24. Brodie ED (1992) Correlational selection for color pattern and antipredator behavior in the garter snake Thamnophis-ordinoides. Evolution 46:1284-1298

25. Bro-Jørgensen J (2010) Dynamics of multiple signalling systems: animal communication in a world in flux. Trends Ecol Evol 25:292-300

26. Brumm H (2004) The impact of environmental noise on song amplitude in a territorial bird. J Anim Ecol 73:434-440

27. Brumm H, Voss K, Kollmer I, Todt D (2003) Acoustic communication in noise: regulation of call characteristics in a New World monkey. J Exp Biol 207:443-448

28. Bullock TH, Hamstra RH Jr, Scheich H (1972) The jamming avoidance response of high frequency electric fish. J Comp Physiol 77:1-22
29. Candolin U (2000) Increased signalling effort when survival prospects decrease: male-male competition ensures honesty. Anim Behav 60:417-422

30. Carleton KL, Parry JWL, Bowmaker JK, Hunt DM, Seehusen O (2005) Colour vision and speciation in Lake Victoria cichlids of the genus Pundamilia. Mol Ecol 14:4341-4353

31. Catania KC (2005) Evolution of sensory specializations in insectivores. Anat Rec A 287:1038-1050

32. Chapman BB, Morrell LJ, Krause J (2009) Plasticity in male courtship behaviour as a function of light intensity in guppies. Behav Ecol Sociobiol 63:1757-1763

33. Chapman BB, Morrell LJ, Tosh CR, Krause J (2010) Behavioural consequences of sensory plasticity in guppies. Proc R Soc B 277:1395-1401

34. Cheroske AG, Cronin TW, Caldwell RL (2003) Adaptive color vision in Pullosquilla litoralis (Stomatopoda, Lysiosquilloidea) associated with spectral and sensitivity changes in light environment. J Exp Biol 206:373-379

35. Cheroske AG, Barber PH, Cronin TW (2006) Evolutionary variation in the expression of phenotypically plastic color vision in Caribbean mantis shrimp genus Neogonodactylus. Mar Biol 150:213-220

36. Christy JH (1995) Mimicy, mate choice, and the sensory trap hypothesis. Am Nat 146:171-181

37. Christy JH, Backwell PRY, Goshima S, Kreutal T (2002) Sexual selection for structure building by courting male fiddler crabs: an experimental study of behavioural mechanisms. Behav Ecol $13: 366-374$

38. Christy JH, Baum JK, Backwell PRY (2003) Attractiveness of sand hoods built by courting male fiddler crabs, Uca musica: test of a sensory trap hypothesis. Anim Behav 66:89-94

39. Clark DL (2011) Spectral reflectance and communication in the wolf spider, Schizocosa ocreata (Hentz): simultaneous crypsis and background contrast in visual signals. Behav Ecol Sociobiol 65:1237-1247

40. Cogălniceanu D (1994) The relative importance of vision and olfaction in mate recognition in male newts (genus Triturus). Herpetologica 50:344-349

41. Cronin TW, Caldwell RL (2002) Tuning of photoreceptor function in three mantis shrimp species that inhabit a range of depths. II. Filter pigments. J Comp Physiol A 188:187-197

42. Cronin TW, Caldwell RL, Marshall J (2001) Sensory adaptation: tunable colour vision in the mantis shrimp. Nature 411:547-548

43. Cummings ME, Rosenthal GG, Ryan MJ (2003) A private ultraviolet channel in visual communication. Proc R Soc B 270:897-904

44. Curtis CC, Stoddard PK (2003) Mate preference in female electric fish, Barchyhypopmus pinnicaudatus. Anim Behav 66:329-336

45. Daniel JC, Blumstein DT (1998) A test of the acoustic adaptation hypothesis in four species of marmots. Anim Behav 56:1517-1528

46. David CT, Kennedy JS, Ludlow AR, Perry JN, Wall C (1982) A reappraisal of insect flight towards a distant point source of wind-borne odor. J Chem Ecol 8:1207-1215

47. de la Haye KL, Spice JI, Widdicombe S, Briffa M (2012) Reduced $\mathrm{pH}$ sea water disrupts chemo-responsive behaviour in an intertidal crustacean. J Exp Mar Biol Ecol 31:134-140

48. de la Torre S, Snowdon CT (2002) Environmental correlates of vocal communication of wild pygmy marmosets, Cebuella pygmaea. Anim Behav 63:847-856

49. De Serrano AR, Weadick CJ, Price AC, Rodd FH (2012) Seeing orange: prawns tap into a pre-existing sensory bias of the Trinidadian guppy. Proc R Soc B 270:3321-3328

50. Denny MW (1993) Air and water: the biology and physics of life's media. Princeton University Press, Princeton 
51. Denoël M, Doellen J (2010) Displaying in the dark: lightdependent alternative mating tactics in the Alpine newt. Behav Ecol Sociobiol 64:1171-1177

52. Derryberry EP (2009) Ecology shapes birdsong evolution: variation in morphology and habitat explains variation in whitecrowned sparrow song. Am Nat 174:24-33

53. Dingle C, Halfwert W, Slabbekoorn H (2008) Habitat-dependent song divergence at subspecies level in the grey-breasted woodwren. J Evol Biol 21:1079-1089

54. Doherty JA (1985) Temperature coupling and 'trade-off' phenomena in the acoustic communication system of the cricket, Gryllus bimaculatus De Geer (Gryllidae). J Exp Biol 114:17-35

55. Doucet SM, Montgomerie R (2003) Bower location and orientation in Satin Bowerbirds: optimising the conspicuousness of male display? Emu 103:105-109

56. Eeva T, Lehikoinen E, Rönkä M (1998) Air pollution fades the plumage of the Great Tit. Funct Ecol 12:607-612

57. Eklöf JA, Svensson M, Rydell J (2002) Northern bats, Eptesicus nilssonii use vision but not flutter-detection when searching for prey in clutter. Oikos 99:347-351

58. Elkinton JS, Schal CS, Cardé RT (1987) Pheromone puff trajectory and the upwind flight of male gypsy moths in a forest. Physiol Entomol 12:399-406

59. Endler JA (1980) Natural selection on color patterns in Poecilia reticulata. Evolution 34:76-91

60. Endler JA (1983) Natural and sexual selection on color patterns in Poeciliid fishes. Evol Biol Fishes 9:173-190

61. Endler JA (1987) Predation, light intensity and courtship behaviour in Poecilia reticulata. Anim Behav 35:1376-1385

62. Endler JA (1990) On the measurement and classification of color in studies of animal colour patterns. Biol J Linn Soc Lond 41:315-352

63. Endler JA (1991) Variation in the appearance of guppy color patterns to guppies and their predators under different visual conditions. Vision Res 31:587-608

64. Endler JA (1992) Signals, signal conditions, and the direction of evolution. Am Nat 139:125-153

65. Endler JA (1993) The color of light in forests and its implications. Ecol Monogr 63:1-27

66. Endler JA (1993) Some general-comments on the evolution and design of animal communication-systems. Philos Trans R Soc B 340:215-225

67. Endler JA (1995) Multiple-trait coevolution and environmental gradients in guppies. Trends Ecol Evol 10:22-29

68. Endler JA (1997) Light, behavior and conservation of forestdwelling organisms. In: Clemmons JR, Buchholz R (eds) Behavioral approaches to conservation in the wild. Cambridge University Press, Cambridge, pp 330-356

69. Endler JA (2000) Evolutionary implications of the interaction between animal signals and the environment. In: Espmark Y, Amundsen, Rosenqvist G (eds) Adaptive significance of signalling and signal design in animal communication. Proceedings of the fifth international Kongsvoll symposium, September 15-20, 1998. Tapir Publishers, Norway, pp 11-46

70. Endler JA, Basolo AL (1998) Sensory ecology, receiver biases and sexual selection. Trends Ecol Evol 13:415-420

71. Endler JA, Day BD (2006) Ornament colour selection, visual contrast and the shape of colour preference functions in great bowerbirds, Chlamydera nuchalis. Anim Behav 72:1405-1416

72. Endler JA, Houde AE (1995) Geographic-variation in female preferences for male traits in Poecilia reticulata. Evolution 49:456-468

73. Endler JA, Théry M (1996) Interacting effects of lek placement, display behavior, ambient light and color patterns in three neotropical forest-dwelling birds. Am Nat 148:421-452
74. Endler JA, Basolo AL, Glowacki S, Zerr J (2001) Variation in response to artificial selection for light sensitivity in guppies. Am Nat 158:36-48

75. Endler JA, Westcott DA, Madden JR, Robson T (2005) Animal visual systems and the evolution of color patterns: sensory processing illuminates signal evolution. Evolution 59:1795-1818

76. Evans MR, Norris K (1996) The importance of carotenoids in signaling during aggressive interactions between male firemouth cichlids (Cichlasoma meeki). Behav Ecol 7:1-6

77. Ey E, Fischer J (2009) The "acoustic adaptation hypothesis"-a review of the evidence from birds, anurans and mammals. Bioacoustics 19:21-48

78. Ey E, Rahn C, Hammerschmidt K, Fischer J (2009) Wild female olive baboons adapt their grunt vocalizations to environmental conditions. Ethology 115:493-503

79. Fabian NJ, Albright LB, Gerlach G, Fisher HS, Rosenthal GG (2007) Humic acid interferes with species recognition in zebrafish (Danio rerio). J Chem Ecol 33:2090-2096

80. Fernandez AA, Morris MR (2007) Sexual selection and trichromatic color vision in primates: statistical support for the preexisting-bias hypothesis. Am Nat 170:10-20

81. Fisher HS, Wong BBM, Rosenthal GG (2006) Alteration of the chemical environment disrupts communication in a freshwater fish. Proc R Soc B 273:1187-1193

82. Fleishman LJ (1992) The influence of the sensory system and the environment on motion patterns in the visual displays of anoline lizards and other vertebrates. Am Nat 139:S36-S61

83. Forrest TG (1991) Power output and efficiency of sound production by crickets. Behav Ecol 2:327-338

84. Fox JE (2004) Chemical communication threatened by endocrinedisrupting chemicals. Environ Health Perspect 112:648-653

85. Francis CD, Ortega CP, Cruz A (2011) Vocal frequency change reflects different responses to anthropogenic noise in two suboscine tyrant flycatchers. Proc R Soc B 278:2025-2031

86. Frith CB, Frith DW (2004) The Bowerbirds: Ptilonorhynchidae. Oxford University Press, Oxford

87. Fuller RC (2002) Lighting environment predicts the relative abundance of male colour morphs in bluefin killifish (Lucania goodei) populations. Proc R Soc B 269:1457-1465

88. Fuller RC, Noa LA (2010) Female preferences, lighting environment, and a test of the sensory bias hypothesis in bluefin killifish. Anim Behav 80:23-35

89. Fuller RC, Travis J (2004) Genetics, lighting environment and heritable responses to lighting environment affect male colour morph expression in bluefin killifish, Lucania goodei. Evolution 58:1086-1098

90. Fuller RC, Fleishman J, Leal M, Travis J, Loew E (2003) Intraspecific variation in retinal cone distribution in the bluefin killifish, Lucania goodei. J Comp Physiol A 190:147-154

91. Fuller RC, Carleton KL, Fadool JM, Spady TC, Travis J (2005) Genetic and environmental variation in the visual properties of bluefin killifish, Lucania goodei. J Evol Biol 18:516-523

92. Fuller RA, Warren PH, Gaston KJ (2007) Daytime noise predicts nocturnal singing in urban robins. Biol Lett 3:368-370

93. Fuller RC, Noa LA, Strellner RS (2010) Teasing apart the many effects of lighting environment on opsin expression and foraging preference in bluefin killifish. Am Nat 176:1-13

94. Gamble S, Lindholm AK, Endler JA, Brooks R (2003) Environmental variation and the maintenance of polymorphism: the effect of ambient light spectrum on mating behaviour and sexual selection in guppies. Ecol Lett 6:463-472

95. Gerhardt HC, Huber F (2002) Acoustic communication in insects and anurans: common problems and diverse solutions. University of Chicago Press, Chicago 
96. Gerhardt HC, Klump GM (1988) Masking of acoustic signals by the chorus background noise in the green tree frog: a limitation on mate choice. Anim Behav 36:1247-1249

97. Gish SL, Morton ES (1981) Structural adaptations to local habitat acoustics in Carolina wren songs. Zeitschrift für Tierpsychologie 56:74-84

98. Godin JGJ (1995) Predation risk and alternative mating tactics in male Trinidadian guppies (Poecilia reticulata). Oecologia 103:224-229

99. Goller F, Suthers RA (1996) Role of syringeal muscles in controlling the phonology of bird song. J Neurophysiol 75:867-876

100. Gomez D, Théry M (2004) Influence of ambient light on the evolution of colour signals: comparative analysis of a Neotropical rainforest bird community. Ecol Lett 7:279-284

101. Goodwin TW (1984) The biochemistry of the carotenoids, vol 2. Chapman and Hall, London

102. Gordon SD, Uetz GW (2010) Multimodal communication of wolf spiders on different substrates: evidence for behavioural plasticity. Anim Behav 81:367-375

103. Grafe TU, Preininger D, Sztatecsny M, Kasah R, Dehling JM, Proksch S, Hödl W (2012) Multimodal communication in a noisy environment: a case study of the Bornean rock frog Staurois parvus. PLoS ONE 7:e37965

104. Gray SM, Dill LM, Tantu FY, Loew ER, Herder F, KcKinnon JS (2008) Environment-contingent sexual selection in a colour polymorphic fish. Proc R Soc B 275:1785-1791

105. Grether GF, Hudon J, Millie DF (1999) Carotenoid limitation of sexual coloration along an environmental gradient in guppies. Proc R Soc B 266:1317-1322

106. Grether GF, Kolluru GR, Rodd FH, Cerda J, Shimazaki K (2005) Carotenoid availability affects the development of a colour-based mate preference and the sensory bias to which it is genetically linked. Proc R Soc B 272:2181-2188

107. Gross MR, Suk HY, Robertson CT (2007) Courtship and genetic quality: asymmetric males show their best side. Proc R Soc B $1622: 2115-2122$

108. Halfwerk W, Holleman LJM, Lessells CM, Slabbekoorn H (2011) Negative impact of traffic noise on avian reproductive success. J Appl Ecol 48:210-219

109. Hart NS, Lisney TJ, Collin SP (2006) Cone photoreceptor oil droplet pigment is affected by ambient light intensity. J Exp Biol 209:4776-4787

110. Heinsohn R, Legge S, Endler JA (2005) Extreme reversed sexual dichromatism in a bird without sex role reversal. Science 309:617-619

111. Heuschele J, Candolin U (2007) An increase in $\mathrm{pH}$ boosts olfactory communication in sticklebacks. Biol Lett 3:411-413

112. Houde AE, Endler JA (1990) Correlated evolution of female mating preferences and male color patterns in the guppy Poecilia reticulata. Science 248:1405-1408

113. Husak JF, Macedonia JM, Fox SF, Sauceda RC (2006) Predation cost of conspicuous male coloration in collared lizards (Crotaphytus collaris): an experimental test using clay-covered model lizards. Ethology 112:572-580

114. Jensen KK, Klokker S (2006) Hearing sensitivity and critical ratios of hooded crows (Corvus corone cornix). J Acoust Soc Am 119:1269-1276

115. Johnson JB, Basolo AL (2003) Visual exposure to a natural predator changes female preference for conspicuous male ornaments in the green swordtail. Behav Ecol 14:19-62

116. Johnstone RA (1996) Multiple displays in animal communication: 'backup signals' and 'multiple messages'. Philos Trans R Soc Lond B 351:329-338

117. Kaczorowski RL, Leonard AS, Dornhaus A, Papaj DR (2012) Floral signal complexity as a possible adaptation to environmental variability: a test using nectar-foraging bumblebees, Bombus impatiens. Anim Behav 83:905-913

118. Kaiser K, Scofield DG, Alloush M, Jones RM, Marczak S, Martineau K, Oliva MA (2011) When sounds collide: the effect of anthropogenic noise on a breeding assemblage of frogs in Belize, Central America. Behaviour 148:215-232

119. Kirschel ANG, Blumstein DT, Cohen RE, Buermann W, Smith TB, Slabbekoorn H (2009) Birdsong tuned to the environment: green hylia song varies with elevation, tree cover and noise. Behav Ecol 20:1089-1095

120. Kroger RHH, Campbell MCW, Fernald RD (2001) The development of the crystalline lens is sensitive to visual input in the African cichlid fish, Haplochromis burtoni. Vision Res 41:549-559

121. Krubitzer L, Kaas JH (2006) The evolution of the neocortex in mammals: how is phenotypic diversity generated? Curr Opin Neurobiol 15:444-453

122. Kulahci IG, Dornhaus A, Papaj DR (2008) Multimodal signals enhance decision making in foraging bumble-bees. Proc R Soc B 275:797-802

123. Lardner B, Mb Lakim (2002) Animal communication: tree-hole frogs exploit resonance effects. Nature 420:475

124. LeBas NR, Marshall NJ (2000) The role of colour in signalling and male choice in the agamid lizard Ctenophorus ornatus. Proc R Soc B 267:445-452

125. Leduc AOHC, Roh E, Brown GE (2009) Effects of acid rainfall on juvenile Atlantic salmon (Salmo salar) antipredator behaviour: loss of chemical alarm function and potential survival consequences during predation. Mar Freshw Res 60:1223-1230

126. Lengagne T, Aubin T, Jouventin P, Lauga J (1999) Acoustic communication in a king penguin colony: importance of bird location within the colony and of the body position of the listener. Polar Biol 21:262-268

127. Levine JSJ, MacNichol EF (1982) Color vision in fishes. Sci Am 246:140-149

128. Locatello L, Rasotto MB, Evans JP, Pilastro A (2006) Colourful male guppies produce faster and more viable sperm. J Evol Biol 19:1595-1602

129. Long KD, Houde AE (1989) Orange spots as a visual cue for female mate choice in the guppy (Poecilia reticulata). Ethology 82:316-324

130. Long KD, Rosenqvist G (1998) Changes in male guppy courting distance in response to a fluctuating light environment. Behav Ecol Sociobiol 44:77-83

131. Lonsdale DJ, Frey MA, Snell TW (1998) The role of chemical signals in copepod reproduction. J Mar Syst 15:1-12

132. Luther D (2008) The influence of the acoustic community on songs of birds in a Neotropical rain forest. Behav Ecol 20:864-871

133. Lythgoe JN (1979) The ecology of vision. Oxford University Press, London

134. Lythgoe JN, Partridge JC (1989) Visual pigments and the acquisition of visual information. J Exp Biol 146:1-20

135. Maan ME, Hofker KD, Van Alphen JJM, Seehausen O (2006) Sensory drive in cichlid speciation. Am Nat 167:947-954

136. MacDonald DW (1985) Social odours in mammals. Clarendon, Oxford

137. Maklakov AA, Simpson SS, Zajitschek F, Hall MD, Dessman J, Clissolg F, Raubenheimer D, Bonduriansky R, Brooks R (2008) Sex-specific fitness effects on nutrition intake on reproduction and lifespan. Curr Biol 18:1-5

138. Marchand D, NcNeil JN (2000) Effects of wind speed and atmospheric pressure on mate searching behavior in the aphid parasitoid Aphidius nigripes (Hymenoptera: Aphidiidae). J Insect Behav 13:19-187 
139. Marchetti K (1993) Dark habitats and bright birds illustrate the role of the environment in species divergence. Nature 362:149-152

140. Marshall J (2000) Communication and camouflage with the same 'bright' colours in reef fishes. Philos Trans R Soc B 355:1243-1248

141. Martin WF (1971) Mechanics of vocalizations in the toad genus Bufo: passive elements. J Exp Zool 176:273-294

142. Martin J, Lopez P (2008) Female sensory bias may allow honest chemical signaling by male Iberian rock lizards. Behav Ecol Sociobiol 62:1927-1934

143. McDonough LM, Brown DF, Aller WC (1989) Insect sex pheromones: effect of temperature on evaporation rates of acetates from rubber septa. J Chem Ecol 15:779-790

144. McLennan DA (2003) The importance of olfactory signals in gasterosteid mating systems: sticklebacks go multimodal. Biol J Linn Soc Lond 80:555-572

145. McNett GD, Luan LH, Cocroft RB (2010) Wind-induced noise alters signaler and receiver behavior in vibrational communication. Behav Ecol Sociobiol 64:2043-2051

146. Miller PJO, Biassoni N, Samuels A, Tyack PL (2000) Whale songs lengthen in response to sonar. Nature 405:309

147. Mitani JC, Stuht J (1998) The evolution of nonhuman primate loud calls: acoustic adaptation for long-distance transmission. Primates 39:171-182

148. Moore P, Crimaldi J (2004) Odor landscapes and animal behavior: tracking odor plumes in different physical worlds. J Mar Syst 49:55-64

149. Moore PA, Grills JL, Schneider RWS (2000) Habitat-specific signal structure for olfaction: an example from artificial streams. J Chem Ecol 26:565-584

150. Morrongiello JR, Bond NR, Crook DA, Wong BBM (2010) Nuptial coloration varies with ambient light environment in a freshwater fish. J Evol Biol 23:2718-2725

151. Morton ES (1975) Ecological sources of selection on avian sounds. Am Nat 109:17-34

152. Müller-Schwarze D, Quay WB, Brundin A (1977) The caudal gland in reindeer (Rangifer tarandus L.): its behavioral role, histology, and chemistry. J Chem Ecol 5:483-517

153. Munoz NE, Blumstein DT (2012) Multisensory perception in uncertain environments. Behav Ecol 23:457-462

154. Nemeth E, Brumm H (2010) Birds and anthropogenic noise: are urban songs adaptive? Am Nat 4:465-475

155. Nemeth E, Winkler H, Dabelsteen T (2001) Differential degradation of antbird songs in a Neotropical rainforest: adaption to perch height. J Acoust Soc Am 110:3263-3274

156. Niven JE, Laughlin SB (2008) Energy limitation as a selective pressure on the evolution of sensory systems. J Exp Biol 211:1792-1804

157. Niven JE, Anderson JC, Laughlin SB (2007) Fly photoreceptors demonstrate energy-information trade-offs in neural coding. PLoS Biol 5:e116

158. O'Loghlen AL, Rothstein SI (2010) Multimodal signalling in a songbird: male audiovisual displays vary significantly by social context in brown-headed cowbirds. Anim Behav 79:1285-1292

159. Olsén HK (2011) Effects of pollutants on olfactory mediated behaviors in fish and crustaceans. Chem Commun Crustac 5:507-529

160. Ord TJ, Peters RA, Clucas B, Stamps JA (2007) Lizards speed up visual displays in noisy motion habitats. Proc R Soc B 274:1057-1062

161. Peters RA, Evans CS (2003) Design of the Jacky dragon visual display: signal and noise characteristics in a complex moving environment. J Comp Physiol A 189:447-459

162. Peters RA, Hemmi JM, Zeli J (2007) Signaling against the wind: modifying motion-signal structure in response to increased noise. Curr Biol 17:1231-1234
163. Proctor HC (1991) Courtship in the water mite Neumania papillator: males capitalize on female adaptations for predation. Anim Behav 42:589-598

164. Proctor HC (1992) Sensory exploitation and the evolution of male mating behaviour: a cladistic test using water mites (Acari: Parasitengona). Anim Behav 44:745-752

165. Pruett-Jones SG, Pruett-Jones MA (1990) Sexual selection through female choice in Lawes' parotia, a lek-mating bird of paradise. Evolution 44:486-501

166. Rand AS, Bridarolli ME, Dries L, Ryan MJ (1997) Light levels influence female choice in Tungara frogs: predation risk assessment? Copeia 1997:447-450

167. Regnier FE, Goodwin M (1977) On the chemical and environmental modulation of pheromone release from vertebrate scent marks. In: Chemical signals in vertebrates, vol 1. Plenum, New York

168. Reimchen TE (1989) Loss of nuptial color in threespine sticklebacks (Gasterosteus aculeatus). Evolution 43:450-460

169. Rice WR (1982) Acoustical location of prey by the marsh hawk: adaptation to concealed prey. Auk 99:403-413

170. Rice AN, Land BR, Bass AH (2011) Nonlinear acoustic complexity in a fish 'two-voice' system. Proc R Soc B 278:3762-3768

171. Rick IP, Modarressie R, Bakker TCM (2006) UV wavelengths affect female mate choice in three-spined sticklebacks. Anim Behav 71:307-313

172. Riesch R, Deecke VB (2011) Whistle communication in mammal-eating killer whales (Orcinus orca): further evidence for acoustic divergence between ecotypes. Behav Ecol Sociobiol 65:1377-1387

173. Rodd FH, Hughes KA, Grether GF, Baril CT (2002) A possible non-sexual origin of mate preference: are male guppies mimicking fruit? Proc R Soc B 269:475-481

174. Ryan MJ (1985) Energetic efficiency of vocalizations of the frog Physalaemus pustulosus. J Exp Biol 116:47-52

175. Ryan MJ (1990) Sexual selection, sensory systems and sensory exploitation. Oxf Surv Evol Biol 7:157-195

176. Ryan MJ, Rand AS (1990) The sensory basis of sexual selection for complex calls in the tungara frog, Physalaemus pustulosus (sexual selection for sensory exploitation). Evolution 44:305-314

177. Ryan MJ, Rand AS (1993) Sexual selection and signal evolution: the ghost of biases past. Philos Trans Biol Sci 340:187-195

178. Ryan MJ, Cocroft RB, Wilcynski W (1990) The role of environmental selection in the intraspecific divergence of mate recognition signals in the cricket frog, Acris crepitans. Evolution 44:1869-1872

179. Schartau JM, Sjogreen B, Gagnon YL, Kroger RHH (2009) Optical plasticity in the crystalline lenses of the cichlid fish Aequidens pulcher. Curr Biol 19:122-126

180. Schaub A, Ostwald J, Siemers BM (2008) Foraging bats avoid noise. J Exp Biol 211:3174-3180

181. Schmidt AKD, Römer H (2011) Solutions to the cocktail party problem in insects: selective filters, spatial release from masking and gain control in tropical crickets. PLoS ONE 6:e28593

182. Scott RJ (2001) Sensory drive and nuptial colour loss in the three-spined stickleback. J Fish Biol 59:1520-1528

183. Seehausen O, van Alphen JJM, Witte F (1997) Cichlid fish diversity threatened by eutrophication that curbs sexual selection. Science 277:1808-1811

184. Seehausen O, Terai Y, Magalhaes IS, Carleton KJ, Mrosso HDJ, Miyagi R, Sluijs I, Schneider MV, Mann ME, Tachida H, Imai H, Okada N (2008) Speciation through sensory drive in cichlid fish. Nature 455:620-626

185. Shand J, Partridge SN, Archer SN, Potts WG, Lythgoe JN (1988) Spectral absorbance changes in the violet/blue sensitive cones of the juvenile pollack, Pollachius pollachius. J Comp Physiol A 163:699-703 
186. Shand J, Davies WL, Thomas N, Balmer L, Cowing JA, Pointer M, Carvalho LS, Trezise AEO, Collin SP, Beazley LD, Hunt DM (2008) The influence of ontogeny and light environment on the expression of visual pigment opsins in the retina of the black bream, Acanthopagrus butcheri. J Exp Biol 211:1495-1503

187. Silva A, Perrone R, Macadar O (2007) Environmental, seasonal, and modulations of basal activity in a weakly electric fish. Physiol Behav 90:525-536

188. Slabbekoorn H, der Boer-Vissor A (2006) Cities change the songs of birds. Curr Biol 16:2326-2331

189. Slabbekoorn H, Peet M (2003) Birds sing at a higher pitch in urban noise. Nature 424:267

190. Slabbekoorn H, Ellers J, Smith TB (2002) Birdsong and sound reverberation: the benefits of reverberation. Condor 104:564

191. Smith C, Barber I, Wootton RJ, Chittka L (2004) A receiver bias in the origin of three-spined stickleback mate choice. Proc R Soc B 271:949-955

192. Snell-Rood EC, Badyaev AV (2008) Ecological gradient of sexual selection: elevation and song elaboration in finches. Oecologia 157:545-551

193. Spence R, Smith C (2008) Innate and learned colour preference in the zebrafish, Danio rerio. Ethology 114:582-588

194. Straw J, Rittschof D (2004) Response of mud snails from low and high imposex sites to sex pheromones. Mar Pollut Bull 48:1048-1054

195. Stuart-Fox DM, Moussalli A, Marshall NJ, Owens IPF (2003) Conspicuous males suffer higher predation risk: visual modelling and experimental evidence from lizards. Anim Behav 66:541-550

196. Sun JWC, Narins PM (2005) Anthropogenic sounds differentially affect amphibian call rate. Biol Conserv 121:419-427

197. Tan EW, Nizar JM, Carrera GE, Fortune ES (2005) Electrosensory interference in naturally occurring aggregates of a species of weakly electric fish, Eigenmannia virescens. Behav Brain Res 164:83-92

198. Théry M, Pincebourde S, Feer F (2008) Dusk light environment optimizes visual perception of conspecifics in a crepuscular horned beetle. Behav Ecol 19:627-634

199. Thomas ML, Gray B, Simmons LW (2011) Male crickets alter the relative expression of cuticular hydrocarbons when exposed to different acoustic environments. Anim Behav 82:49-53

200. Tobias JA, Aben J, Brumfield RT, Derryberry EP, Halfwerk W, Slabbekoorn H, Seddon N (2010) Song divergence by sensory drive in Amazonian birds. Evolution 64:2820-2839

201. Turner AM, Chislock MF (2010) Blinded by the stink: nutrient enrichment impairs the perception of predation risk by freshwater snails. Ecol Appl 20:2089-2095

202. Uetz GW, Roberts JA, Taylor PW (2009) Multimodal communication and mate choice in wolf spiders: female response to multimodal versus unimodal signals. Anim Behav 78:299-305

203. Uy JAC, Endler JA (2004) Modification of the visual background increases the conspicuousness of golden-collared manakin displays. Behav Ecol 15:1003-1010

204. Vasconcelos RO, Amorim MCP, Ladich F (2007) Effects of ship noise on the detection of communication signals in the Lusitanian toadfish. J Exp Biol 210:2104-2112
205. Ward AJW, Duff AJ, Horsfall JS, Currie S (2007) Scents and scents-ability: pollution disrupts chemical social recognition and shoaling in fish. Proc R Soc B 275:101-105

206. Waser P, Waser MS (1977) Experimental studies of primate vocalization: specializations for long-distance propagation. Zeitschrift für Tierpsychologie 43:239-263

207. Weadick CJ, Chang BSW (2007) Long-wavelength sensitive visual pigments of the guppy (Poecilia reticulata): six opsins expressed in a single individual. BMC Evol Biol 7:S11

208. Weissburg MJ, Zimmer-Faust RK (1993) Life and death in moving fluids: hydrodynamic effects on chemosensory-mediated predation. Ecology 74:1428-1443

209. Wemmer C, Murtaugh J (1980) Chemical signals: vertebrates and aquatic invertebrates. Plenum, New York

210. West-Eberhard MJ (1984) Sexual selection, competitive communication and species-specific signals in insects. Insect communication. Academic Press, New York

211. Wiley RH (1991) Associations of song properties with habitats for territorial oscine birds of Eastern North America. Am Nat 138:973-993

212. Wiley RH, Richards DG (1978) Physical constraints on acoustic communication in the atmosphere: implications for the evolution of animal vocalizations. Behav Ecol Sociobiol 3:69-94

213. Wilgers DJ, Hebets EA (2011) Complex courtship displays facilitate male reproductive success and plasticity in signalling across variable environments. Curr Zool 57:175-186

214. Witte K, Farris HE, Ryan MJ, Wilczynski W (2005) How cricket frog females deal with a noisy world: habitat-related differences in auditory tuning. Behav Ecol 16:571-579

215. Wolf MC, Martin AL III, Simon JL, Bergner JL, Moore PA (2009) Chemosensory signals in stream habitats: implications for ecological interactions. J N Am Benthol Soc 28:560-571

216. Wollerman L, Wiley H (2002) Background noise from a natural chorus alters female discrimination of male calls in a Neotropical frog. Anim Behav 63:15-22

217. Wong BBM, Candolin U, Lindström K (2007) Environmental deterioration compromises socially enforced signals of male quality in three-spined sticklebacks. Am Nat 170:184-189

218. Yokoyama S (2000) Phylogenetic analysis and experimental approaches to study color vision in vertebrates. In: Methods in enzymology: vertebrate phototransduction and the visual cycle, part A. Academic Press, San Diego

219. Yokoyama S (2002) Molecular evolution of vertebrate visual pigments. Prog Retin Eye Res 19:385-419

220. Zelick RD, Narins PM (1983) Intensity discrimination and the precision of call timing in two species of neotropical treefrogs. J Comp Physiol 153:403-412

221. Zeyl JN, Laberge F (2011) Multisensory signals trigger approach behaviour in the fire-bellied toad Bombina orientalis: sex differences and call specificity. Zoology 114:369-377

222. Zhou S, Stone EA, Mackay TFC, Anholt RRH (2009) Plasticity of the chemoreceptor repertoire in Drosophila melanogaster. PLoS Genet 5:e1000681

223. Zimmer-Faust RK (1991) Chemical signal-to-noise detection by spiny lobsters. Biol Bull 181:419-426 